\title{
A Preliminary Life Cycle Analysis of Bioethanol Production Using Seawater in a Coastal Biorefinery Setting
}

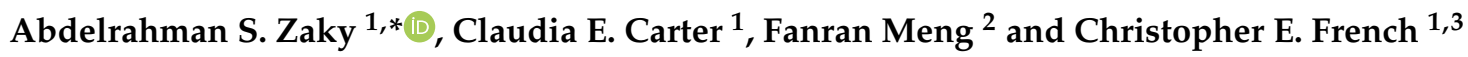 \\ 1 School of Biological Sciences, University of Edinburgh, King's Buildings, Edinburgh EH9 3FF, UK; \\ cloudycarter@gmail.com (C.E.C.); c.french@ed.ac.uk (C.E.F.) \\ 2 Department of Engineering, University of Cambridge, Trumpington Street, Cambridge CB2 1PZ, UK; \\ fm392@cam.ac.uk \\ 3 Zhejiang University-University of Edinburgh Joint Research Centre for Engineering Biology, \\ International Campus, Zhejiang University, Haining 314400, China \\ * Correspondence: A.Zaky@ed.ac.uk or A.Zaky@cu.edu.eg; Tel.: +44-74744440333
}

Citation: Zaky, A.S.; Carter, C.E.; Meng, F.; French, C.E. A Preliminary Life Cycle Analysis of Bioethanol Production Using Seawater in a Coastal Biorefinery Setting. Processes 2021, 9, 1399. https://doi.org/ $10.3390 /$ pr9081399

Academic Editors: Antonio D. Moreno and Paloma Manzanares

Received: 26 July 2021

Accepted: 10 August 2021

Published: 13 August 2021

Publisher's Note: MDPI stays neutral with regard to jurisdictional claims in published maps and institutional affiliations.

Copyright: (c) 2021 by the authors. Licensee MDPI, Basel, Switzerland. This article is an open access article distributed under the terms and conditions of the Creative Commons Attribution (CC BY) license (https:// creativecommons.org/licenses/by/ $4.0 /)$.

\begin{abstract}
Bioethanol has many environmental and practical benefits as a transportation fuel. It is one of the best alternatives to replace fossil fuels due to its liquid nature, which is similar to the gasoline and diesel fuels traditionally used in transportation. In addition, bioethanol production technology has the capacity for negative carbon emissions, which is vital for solving the current global warming dilemma. However, conventional bioethanol production takes place based on an inland site and relies on freshwater and edible crops (or land suitable for edible crop production) for production, which has led to the food vs. fuel debate. Establishing a coastal marine biorefinery (CMB) system for bioethanol production that is based on coastal sites and relies on marine resources (seawater, marine biomass and marine yeast) could be the ultimate solution. In this paper, we aim to evaluate the environmental impact of using seawater for bioethanol production at coastal locations as a step toward the evaluation of a CMB system. Hence, a life cycle assessment for bioethanol production was conducted using the proposed scenario, named Coastal Seawater, and compared to the conventional scenario, named Inland Freshwater (IF). The impact of each scenario in relation to climate change, water depletion, land use and fossil depletion was studied for comparison. The Coastal Seawater scenario demonstrated an improvement upon the conventional scenario in all the selected impact categories. In particular, the use of seawater in the process had a significant effect on water depletion, showing an impact reduction of $31.2 \%$. Furthermore, reductions were demonstrated in natural land transformation, climate change and fossil depletion of $5.5 \%, 3.5 \%$ and $4.2 \%$, respectively. This indicates the positive impact of using seawater and coastal locations for bioethanol production and encourages research to investigate the CMB system.
\end{abstract}

Keywords: bioethanol; LCA; marine fermentation; seawater; Saccharomyces cerevisiae; water footprint; bioenergy; biofuel; marine yeast; GHG

\section{Introduction}

Growing concern regarding the effect of anthropogenic activity on climate change has given the impetus to research greener energy sources. Governments worldwide, including the UK, are committed to reaching the climate change goals detailed in the Paris Agreement [1]. To reach these goals, it is essential to base infrastructure on a framework of sustainable technology not only to reduce emissions, but also to mitigate the environmental changes already generated, such as long-lived carbon dioxide $\left(\mathrm{CO}_{2}\right)$ emissions.

Transportation is a major contributor to climate change, accounting for about $24 \%$ of global $\mathrm{CO}_{2}$ emissions and $21 \%$ of the total GHG emissions; three quarters of these emissions are generated by road vehicles [2,3]. These emissions, along with other greenhouse gases (GHGs), are released from the production and combustion of fossil fuels, mainly coal, gasoline and diesel. In addition, fossil fuels are also a dwindling finite resource. 
Efforts to reduce GHG emissions are looking at green energy sources as a sustainable alternative to fossil fuels for powering vehicles. The prominent candidates are hydrogen and renewable electricity, as well as biofuels including bioethanol, biodiesel and biogas [4]. The implementation of hydrogen in vehicles is hindered by logistical issues in its storage and cost $[5,6]$ while electric power is not yet feasible in many vehicles including watercraft, aircraft, long-distance commuter vehicles and heavy duty vehicles. This is mainly because of challenges in the practical range due to limited battery energy density [7], payload and total cost. In contrast, biofuels are both promising and immediately applicable alternative fuels. Biofuels can offset the carbon released upon combustion during their production.

Bioethanol is a liquid renewable biofuel that is widely used in blends with gasoline to improve the octane rating of the vehicle's engine and reduce its carbon footprint. It is produced through the microbial fermentation of sugars, and these sugars are sourced from biological materials such as sugary and starchy crops (first-generation bioethanol), lignocellulosic biomass (second-generation bioethanol) and seaweed (third-generation bioethanol). During cultivation, these biological materials absorb $\mathrm{CO}_{2}$ from the atmosphere via photosynthetic growth. Furthermore, fermentation of the derived sugars produces a highly pure stream of $\mathrm{CO}_{2}$ and can thus be integrated with carbon capture and storage (CCS) technology [8]. Together with CCS, bioethanol production can achieve the negative emissions necessary to help reach the UN's climate goals. In addition, there are many pathways for carbon capture, storage and utilization (CCSU) (Figure 1), each coming with their own environmental footprints [9]. It has been demonstrated that when linked with carbon sequestration, bioethanol production can be carbon negative. However, it is important that the CCS and carbon utilization pathways are selected with high regard to the environmental impact. For example, if the captured carbon were to be used in enhanced oil recovery, the carbon captured during the bioethanol production process would be brought to zero or even surpassed by the carbon release in combustion of the mined oil.

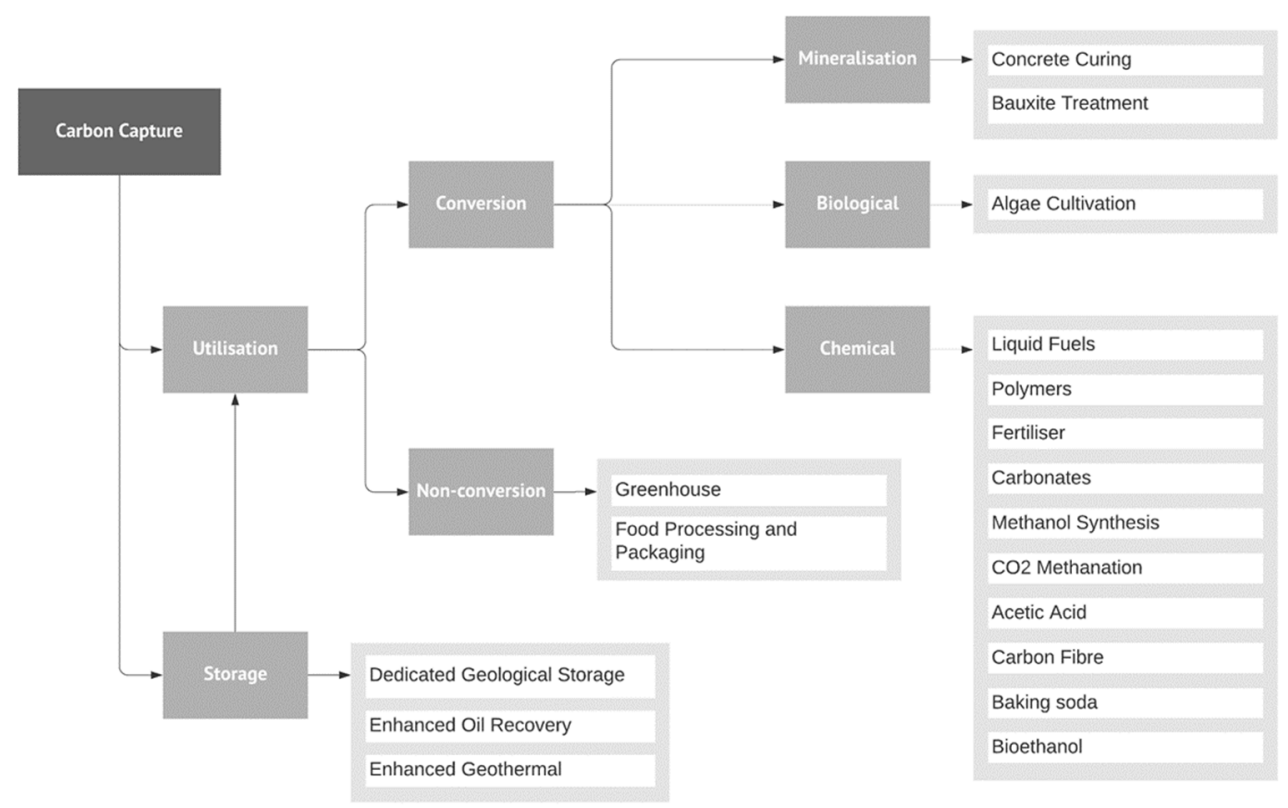

Figure 1. The diagram to illustrate the pathways of carbon utilization and storage post-capture as described in the Global Status Report 2019 of the Global CCS Institute.

Although bioethanol is regarded as a promising alternative fuel, there are some economic, policy and environmental issues associated with the current production processes. For example, a lack of policy to support ethanol-gasoline blending in many countries results in a lack of demand as well as high production costs. While the US government mandates the supply of E10 as a minimum ethanol level, the gasoline served in the UK is 
not regulated and is generally only E5. A production process incurring lesser cost or one that offsets costs with greater earning potential would encourage bioethanol production. This lack of policy support is mainly due to the food security vs. biofuel feedstock supply debate, which regards bioethanol production as a threat to the food supply as it consumes the arable land and freshwater that are vital for producing food crops. A new pathway for bioethanol production that reduces freshwater consumption and arable land use would achieve social acceptance and encourage policy makers to legislate policies that support bioethanol production and utilization.

Weak ethanol-gasoline blends such as E10 and E15 (10\% and 15\% ethanol) can be safely and readily introduced into the supply [10]. It has been shown that blending gasoline with ethanol lowers emissions during combustion [11,12]. The UK government estimated that using the E10 ethanol blend in the UK could cut $\mathrm{CO}_{2}$ from road transport by 750,000 tons per year, which is equivalent to removing 350,000 cars off the roads [13]. Ethanol use in combustion engines offers reductions in emissions and improvements in power and energy efficiency compared with fossil fuels such as diesel and gasoline [14]. Additionally, ethanol is biodegradable and evaporates in open spaces [15]. This means it is unlikely to cause significant damage, environmental or otherwise, upon spillage.

Transforming land for biofuel feedstock cultivation in addition to that necessary for food production, a phenomenon known as land use change (LUC), comes with a severe environmental impact [16] and prompts concerns over food security. For this reason, the Renewable Energy Directive (EU) imposed a 7\% ceiling on the use of bioenergy for transportation when derived from food crops in 2018 [17]. This has prompted a transition from the first-generation biofuels derived from food-based feedstocks such as corn (used in the USA), sugarcane (used in Brazil), wheat and sugar beet (used in the UK) to secondgeneration biofuels, which are derived from non-food lignocellulosic biomass such as wheat straw, switchgrass, willow and miscanthus. Currently in development are third-generation biofuels produced using algal and waste feedstocks requiring no land.

Biofuels can have a greater water footprint (WF) than fossil fuels [18], highlighting the importance of considering a fuel product's impact across its entire life cycle rather than only in combustion. The WF of first-generation bioethanol ranges from 1400 to 9800 liters (L) of freshwater per L of ethanol [19,20], and hence it presents an environmental concern. With much of the world facing water scarcity, there is understandable resistance to bioethanol at the cost of the water supply. Although second-generation bioethanol from crop residues demonstrates a much lower WF [21], the WF can be reduced further by focusing on the entire process rather than the feedstock only. One way to do that is to utilize seawater instead of freshwater for preparing the fermentation medium for bioethanol production. This suggests the construction of biorefinery facilities in a coastal location and using marine yeast strains for fermentation.

Seawater is non-potable and abundant, and therefore its use in industrial-scale fermentation reduces the WF of the product and would not detract from the general water supply [22]. It is also freely available and thus offers a reduction in production cost. Halotolerant yeasts, sourced in the marine environment, would be applied in conjunction with seawater use. This is because they demonstrate improved function in a seawater-based fermentation medium compared with terrestrial yeasts $[19,23]$. The marine yeast strain S. cerevisiae AZ65 produced bioethanol at a higher productivity rate and improved yield using a freshwater-YPD medium and a similar productivity rate and improved yield using a seawater-YPD medium compared with the industrial terrestrial strain $S$. cerevisiae NCYC2592. S. cerevisiae AZ65 was also able to produce bioethanol efficiently using a seawater-molasses medium $[19,24]$.

The aim of this study is to quantify the environmental and cost impacts of bioethanol production using seawater fermentation at a coastal site. The preliminary life cycle and technoeconomic analysis of bioethanol explores three elements: the coastal location, seawater medium and marine yeasts. A comparative study assesses the proposed coastal seawater system as opposed to a conventional bioethanol production system from sugar beet. 


\section{Materials and Methods}

A comparative life cycle assessment (LCA) was conducted to evaluate the production of bioethanol from sugar beet using standard fermentation and seawater fermentation in accordance with the standard methodology guidelines set out in ISO14040 [25]. Analyses were conducted with SimaPro v8 [26], and data were sourced from the Ecoinvent database v3.6 [27] and Agri-footprint database v4.0 [28]. The life cycle impact was assessed using the ReCiPe midpoint hierarchist method with European normalization. This considers 18 environmental impact categories, including climate change, water depletion, land use and fossil depletion. Water and land use were chosen for their pertinence to the current issues in the production of bioethanol. Fossil depletion and climate change are areas in which bioethanol production has already reduced the impacts compared with the use of fossil fuels, and so they were included to ascertain whether they could be further improved with the Coastal Seawater scenario.

\subsection{Goal and Scope}

The goal of this study was to compare the environmental impacts of two approaches for bioethanol production from sugar beet on a cradle-to-gate basis. This study included (a) the conventional production approach using freshwater and inland locations and (b) the proposed approach using seawater at a coastal location.

The system boundary included the feedstock preparation (i.e., sugar beet cultivation), bioethanol conversion, coproduct processing and all necessary transportation within that duration (Figure 2). The construction of infrastructure and subsequent steps, including the use phase of the fuels, were excluded in this study, as the bioethanol products produced by different methods were assumed to be identical. The functional unit was $1 \mathrm{~L}$ bioethanol (95\% bioethanol, $5 \%$ water).

\subsection{Modeling and Input Data}

Each production method was modeled, and the system boundaries were defined for both scenarios. The conventional bioethanol production approach was designated the 'Inland Freshwater' scenario. The system boundary for the Inland Freshwater scenario (Figure 2A) included sugar beet cultivation and harvesting, preparation of the sugar beet syrup required for fermentation, wastewater treatment and the processing required to produce bioethanol and its coproducts.

The proposed model, known hereinafter as the 'Coastal Seawater' scenario, retained identical feedstock and largely the same process as the Inland Freshwater scenario, with the notable differences being seawater use in fermentation, the use of halotolerant yeasts and water processing to obtain additional coproducts. The Coastal Seawater scenario system boundary (Figure 2B) included the pretreatment of the inlet seawater (Figure 2).

The life cycle inventory differed at various points to reflect the differences in efficiencies, processes and stages relating to the different resource use in each scenario (Tables 1-3).

Electricity, sequestered $\mathrm{CO}_{2}$, animal feed and LimeX — an agricultural product for soil $\mathrm{pH}$ correction-all have market value and are thus coproducts of bioethanol production. Production of ethanol along with the coproducts was considered the endpoint for this study. Distribution and use were indicated but not elaborated on, as they were not part of the scope of this study. The wastewater treatment in this scenario was to reduce the environmental impact arising from its disposal. 
A)

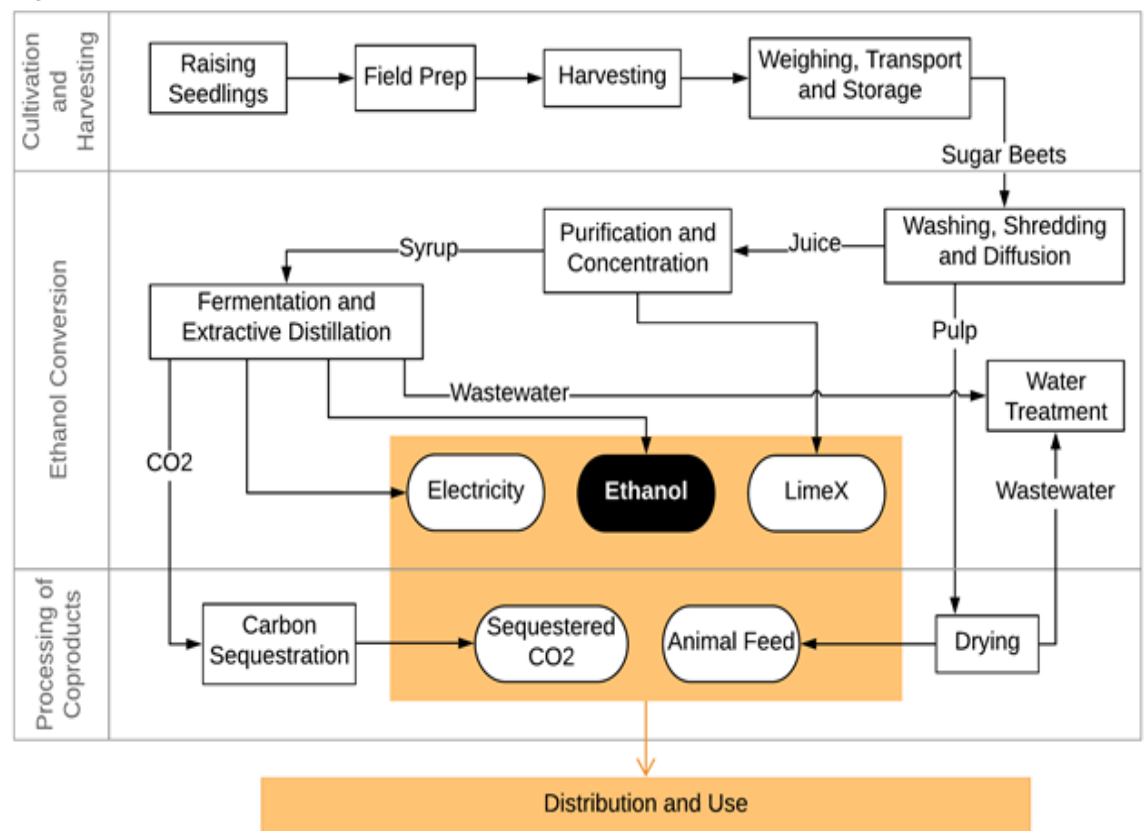

B)

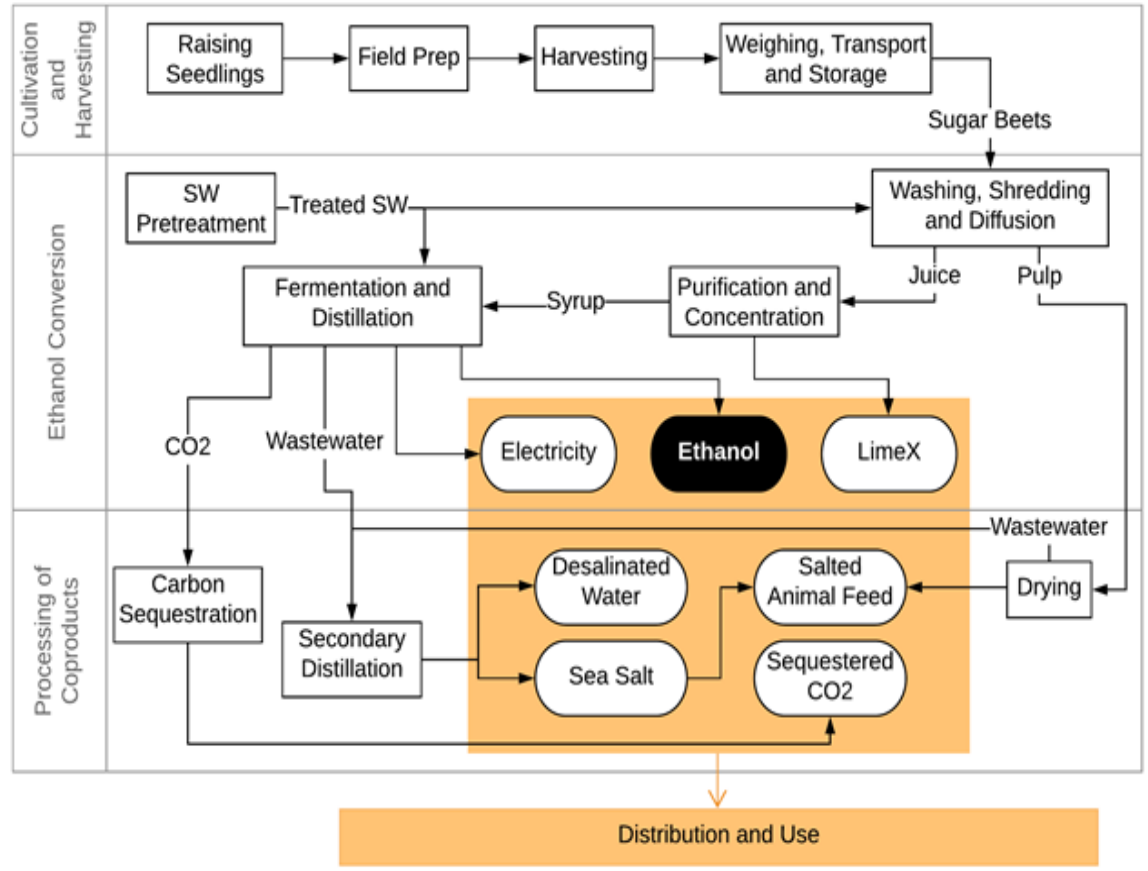

Figure 2. The diagram defining the system boundary of the study, showing the (A) Inland Freshwater scenario and (B) Coastal Seawater scenario. The inclusions are the intermediate stages (on the arrows), processes (rectangle) and final products (rounded) in the production of bioethanol from sugar beet. The swim lanes of the diagram indicate the subsystems. Production of ethanol (black) along with the coproducts (shaded box) were considered the endpoint for this study. Distribution and use are indicated but not elaborated on as it was not part of the scope of this study. 
Table 1. Life cycle inventory for the cultivation and harvesting of sugar beet (SB), which is identical to the Inland Freshwater and Coastal Seawater scenarios.

\begin{tabular}{|c|c|c|}
\hline Input Data & Unit & Inland Freshwater or Coastal Seawater (a) \\
\hline Occupation, arable & $\mathrm{m}^{2} \mathrm{a}$ & 10,000 \\
\hline Water, unspecified natural origin, DE & $\mathrm{m}^{3} / \mathrm{ha}$ & 186.1 \\
\hline Energy from diesel burned in machinery, RER Energy & $\mathrm{MJ} / \mathrm{ha}$ & 7367.25 \\
\hline Manure from pigs, at pig farm, RER Energy & $\mathrm{kg} / \mathrm{ha}$ & 8732.39 \\
\hline $\begin{array}{c}\text { Potassium chloride (NPK 0-0-60) at regional storehouse, } \\
\text { RER Energy }\end{array}$ & $\mathrm{kg} / \mathrm{ha}$ & 162.38 \\
\hline $\begin{array}{c}\text { NPK compound (NPK 15-15-15) at regional storehouse, } \\
\text { RER Energy }\end{array}$ & $\mathrm{kg} / \mathrm{ha}$ & 213.41 \\
\hline $\begin{array}{c}\text { PK compound (NPK 0-22-22) at regional storehouse, } \\
\text { RER Energy }\end{array}$ & $\mathrm{kg} / \mathrm{ha}$ & 91.55 \\
\hline $\begin{array}{c}\text { Potassium sulfate (NPK 0-0-50) at regional storehouse, } \\
\text { RER Energy }\end{array}$ & $\mathrm{kg} / \mathrm{ha}$ & 20.84 \\
\hline $\begin{array}{c}\text { Triple superphosphate as } 80 \% \mathrm{Ca}\left(\mathrm{H}_{2} \mathrm{PO}_{4}\right)_{2}(\mathrm{NPK} 0-48-0) \text { at } \\
\text { regional storehouse, } \mathrm{RER} \text { Energy }\end{array}$ & $\mathrm{kg} / \mathrm{ha}$ & 16.35 \\
\hline $\begin{array}{c}\text { Ammonium sulfate as } 100 \%\left(\mathrm{NH}_{4}\right)_{2} \mathrm{SO}_{4}(\mathrm{NPK} 21-0-0) \text { at } \\
\text { regional storehouse, RER Energy }\end{array}$ & $\mathrm{kg} / \mathrm{ha}$ & 28.55 \\
\hline $\begin{array}{c}\text { Calcium ammonium nitrate (CAN) (NPK 26.5-0-0) at } \\
\text { regional storehouse, RER Energy }\end{array}$ & $\mathrm{kg} / \mathrm{ha}$ & 242.87 \\
\hline $\begin{array}{l}\text { Liquid urea-ammonium nitrate solution (NPK 30-0-0) at } \\
\text { regional storehouse, RER Energy }\end{array}$ & $\mathrm{kg} / \mathrm{ha}$ & 56.34 \\
\hline $\begin{array}{c}\text { Urea as } 100 \% \mathrm{CO}\left(\mathrm{NH}_{2}\right)_{2}(\mathrm{NPK} 46.6-0-0) \text { at regional } \\
\text { storehouse, RER Energy }\end{array}$ & $\mathrm{kg} / \mathrm{ha}$ & 65.94 \\
\hline Lime fertilizer at regional storehouse, RER Energy & $\mathrm{kg} / \mathrm{ha}$ & 290.74 \\
\hline
\end{tabular}

Figure 2B has been constructed using Figure 2A as a basis, with alterations that are specific to the Coastal Seawater scenario. The seawater (SW) treatment stage particular to this scenario produces water that replaces the tap water in the Inland Freshwater scenario for the washing processes and as a fermentation medium. Furthermore, in this system, the so-called wastewaters of the fermentation and drying stages are treated to become a coproduct with a market value rather than being treated for disposal. This also results in the final water treatment being considered part of the 'Processing of Coproducts' subsystem rather than 'Ethanol Conversion'.

\subsubsection{Sugar Beet Cultivation and Harvesting}

Sugar beets are commonly grown in Europe for both food and energy. As a firstgeneration biofuel feedstock, their processing is well-established and practiced by many bioethanol manufacturers [29].

The input data for the cultivation and harvesting subsystem (Table 1) were identical in each scenario and were sourced from the Agri-footprint database [28]. The dataset describes a farm in Germany. This was not considered to significantly differ from UK practices due to the congruent climates and stance on genetically modified crops; thus, there were presumably comparable soil management and application of agrichemicals. 


\subsubsection{Seawater Pretreatment}

It was determined that the seawater should be filtered to remove meso- and macroplankton (i.e., larger than $2 \mathrm{~mm}$ in size) and sand prior to being fed into the fermenters in the Coastal Seawater scenario (Figure 3). Otherwise, these larger elements in the inlet water would be collected in the fermentation vessel and potentially hinder the downstream processing of the distillate and salt products. The flow of the inlet water through a sedimentation tank removed sand, enabling its use for washing the sugar beet. For the portion used in the fermentation media, this was followed by a basic filtration stage with a 2-mm pore equivalence to remove large plankton. Any remaining microorganisms were neutralized by heat in preparation of the fermentation media.

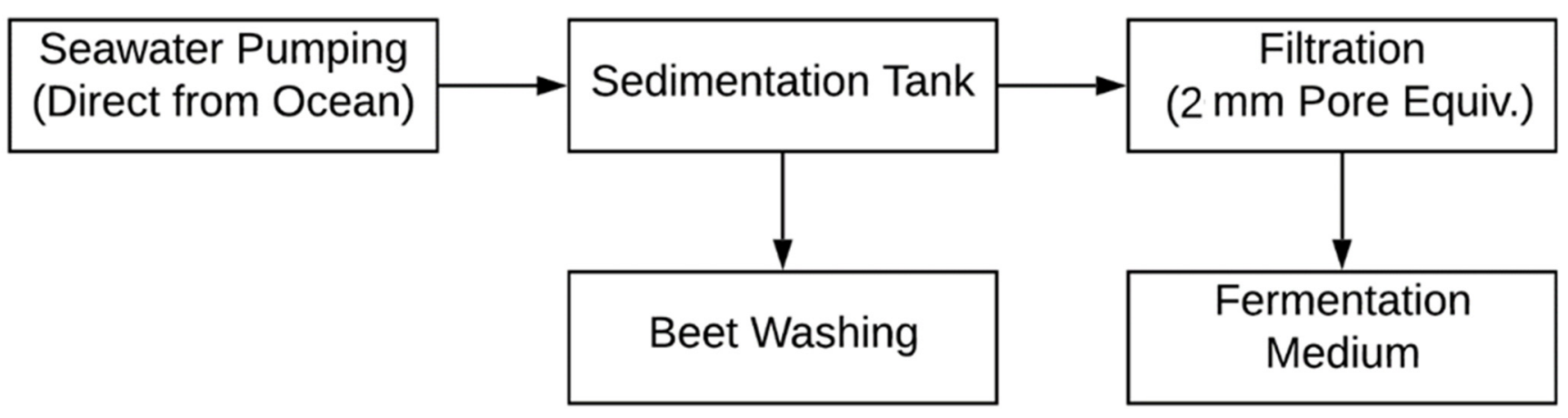

Figure 3. Sedimentation of sand achieves the purity required for sugar beet washing, while a second stage of treatment by filtration prepares the water for use in the fermentation medium. Filtration is granular, with an equivalent pore size of $2 \mathrm{~mm}$ to remove larger planktonic organisms.

The modeled pretreatment stage had few inputs. The use of a sedimentation tank took advantage of natural settling of the sand at the base of the tank due to gravity-a passive process - and the sedimented sand was disposed of by returning it to the ocean. Filtration was achieved by flowing the water over a granular filtration bed, through which it also moved downward by means of gravity. Therefore, the only energy consumption was for pumping the water from the ocean.

\subsubsection{Sugar Beet Washing}

The scenarios involved different resource use in sugar beet washing. The freshly harvested crop needed to be washed to remove soil and stones. Tap water was used in the Inland Freshwater scenario, while clarified seawater was assumed to be used in the Coastal Seawater scenario.

\subsubsection{Syrup Production}

Next, the washed crop in each scenario was shredded, soaked and pressed to release the sugars contained in the root into a juice. Subsequent concentration and purification yielded a syrup with $\sim 65-67 \%(w / w)$ fermentable sugars [30], which is appropriate for yeast fermentation. The solid portion, the pulp, was later processed to become animal feed. 
Table 2. Life cycle inventory of sugar beet to ethanol conversion.

\begin{tabular}{|c|c|c|c|c|}
\hline Input Data & Unit & Inland Freshwater & Seawater Coastal & Source ${ }^{(a)}$ \\
\hline \multicolumn{5}{|c|}{ Washing and Syrup Production } \\
\hline Tap Water & $\mathrm{L} / \mathrm{kg} \mathrm{SB}$ & 5.000 & 0 & [31] \\
\hline Seawater & $\mathrm{L} / \mathrm{kg} \mathrm{SB}$ & 0 & 5.000 & \\
\hline Electricity (Washing) & $\mathrm{kWh} / \mathrm{kg} \mathrm{SB}$ & 4.000 & 4.000 & [32] \\
\hline Hydrochloric Acid & $\mathrm{g} / \mathrm{kg} \mathrm{SB}$ & 0.025 & 0.025 & \multirow{3}{*}{ [33] } \\
\hline Formaldehyde & $\mathrm{g} / \mathrm{kg} \mathrm{SB}$ & 0.150 & 0.150 & \\
\hline LimeX Recovered & $\mathrm{g} / \mathrm{kg} \mathrm{SB}$ & 45.000 & 45.000 & \\
\hline \multicolumn{5}{|c|}{ Water Inlet or Treatment } \\
\hline Wastewater Treatment (for Disposal) & $\mathrm{m}^{3} \mathrm{H}_{2} \mathrm{O} / \mathrm{kg} \mathrm{Et}$ & 3.140 & 0 & [30] \\
\hline Electricity (Seawater Pumping) & $\mathrm{kWh} / \mathrm{m}^{3} \mathrm{H}_{2} \mathrm{O}$ & 0 & 0.004 & [34] \\
\hline \multicolumn{5}{|c|}{ Fermentation } \\
\hline Clean Sugar Beet & $\mathrm{kg} / \mathrm{kg} \mathrm{Et}$ & 8.535 & 8.535 & \multirow{5}{*}{ [27] } \\
\hline Sulfuric Acid & $\mathrm{kg} / \mathrm{kg} \mathrm{Et}$ & 0.026 & 0.026 & \\
\hline Sodium Sulfate & $\mathrm{kg} / \mathrm{kg} \mathrm{Et}$ & 0.003 & 0.003 & \\
\hline Fresh Water for Medium & $\mathrm{L} / \mathrm{kg} \mathrm{Et}$ & 0.814 & 0 & \\
\hline Seawater for Medium & $\mathrm{L} / \mathrm{kg} \mathrm{Et}$ & 0 & 0.814 & \\
\hline Water for Cooling & $\mathrm{kg} / \mathrm{kg} \mathrm{Et}$ & 0.3 & 0.3 & [35] \\
\hline Antiscalant & $\mathrm{g} / \mathrm{kg} \mathrm{SB}$ & 0.040 & 0.040 & \multirow{4}{*}{ [33] } \\
\hline Coke & $\mathrm{g} / \mathrm{kg} \mathrm{SB}$ & 1.800 & 1.800 & \\
\hline Anti-Foam & $\mathrm{g} / \mathrm{kg} \mathrm{SB}$ & 0.200 & 0.200 & \\
\hline Electricity (Surplus) & $\mathrm{kWh} / \mathrm{kg} \mathrm{SB}$ & 0.694 & 0.694 & \\
\hline
\end{tabular}

(a) The sources are references for the Inland Freshwater scenario, while the Seawater Coastal scenario data were assumed to be appropriate.

Table 3. Life cycle inventory for the processing of coproducts.

\begin{tabular}{|c|c|c|c|c|}
\hline Input Data & Unit & Inland Freshwater & Coastal Seawater & Source $^{(a)}$ \\
\hline \multicolumn{5}{|l|}{ Carbon Sequestration } \\
\hline $\mathrm{CO}_{2}$ from Fermentation & $\mathrm{kg} / \mathrm{kg} \mathrm{Et}$ & 0.713 & 0.713 & [27] \\
\hline Electricity & $\mathrm{kWh} / \mathrm{kg} \mathrm{CO} 2$ & $0.105^{(b)}$ & $0.105^{(b)}$ & [36] \\
\hline \multicolumn{5}{|l|}{ Animal Feed Production } \\
\hline Wet Sugar Beet Pulp & $\mathrm{kg} / \mathrm{kg} \mathrm{Et}$ & 1.392 & 1.392 & \multirow[t]{2}{*}{ [27] } \\
\hline Process Steam & $\mathrm{MJ} / \mathrm{kg}$ wet pulp & 1.413 & 1.413 & \\
\hline Electricity for Drying & $\mathrm{MJ} / \mathrm{kg}$ wet pulp & 0.043 & 0.043 & \multirow[t]{2}{*}{ [28] } \\
\hline Dried Sugar Beet Pulp & $\mathrm{kg} / \mathrm{kg}$ wet pulp & 0.243 & 0.243 & \\
\hline \multicolumn{5}{|l|}{$\begin{array}{c}\text { Distillate Water } \\
\text { Treatment }\end{array}$} \\
\hline Water from Distillation & $\mathrm{kg} / \mathrm{L} \mathrm{Et}$ & 0 & 7.000 & \multirow{2}{*}{ [37] } \\
\hline $\begin{array}{c}\text { Sea Salt from } \\
\text { Distillation }\end{array}$ & $\mathrm{kg} / \mathrm{L} \mathrm{Et}$ & 0 & 0.208 & \\
\hline
\end{tabular}

(a) The sources are references for the Inland Freshwater scenario, while the Seawater Coastal scenario data were from assumptions and calculations in this study. ${ }^{(\mathrm{b})}$ Average taken of the range $90-120 \mathrm{kWh}$ stated in the source.

\subsubsection{Fermentation and Ethanol Recovery}

The resultant syrup was fed into industrial-scale bioreactors, in which the yeasts completed the conversion of sugar into bioethanol in anaerobic conditions. Terrestrial Saccharomyces cerevisiae yeasts completed the fermentation in the Inland Freshwater scenario. The productivity of terrestrial S. cerevisiae was inhibited by the salinity of seawater, and therefore the Coastal Seawater scenario was modeled to involve marine yeast [19].

Both scenarios were modeled with ethanol recovery by distillation. In large industrial distillation columns, the product is separated from water, resulting in ethanol of $95 \%$ purity with $5 \%$ water and trace amounts of solvent used in ethanol recovery. 


\subsubsection{Processing of Coproducts}

The coproducts in the Inland Freshwater scenario included $\mathrm{CO}_{2}$ and animal feed only, while in the Coastal Seawater scenario, additional coproducts including sea salt and distilled water were also obtained, and the produced animal feed was supplemented with sea salt. The inventory data for this subsystem are summarized in Table 3. Certain coproducts in the outlined systems were produced via additional processing which was not directly contributory to ethanol production. Processes solely associated with the coproducts were in a distinct subsystem. The biogenic $\mathrm{CO}_{2}$ released was considered a coproduct with many potential commercial uses, as illustrated in Figure 1. The $\mathrm{CO}_{2}$ released as an output of fermentation was assumed to be $100 \%$ pure for the purposes of this study. This reflects an ideal anaerobic fermentation, where one mole of glucose provided corresponds to a yield of two moles of ethanol and two moles of $\mathrm{CO}_{2}$ only. Consequently, the $\mathrm{CO}_{2}$ stream from the fermentation vessel only required treatment by compression for storage.

As a part of the CCS process, the $\mathrm{CO}_{2}$ stream was compressed (necessitating an electricity supply) in preparation as a coproduct. However, the full pathway of the $\mathrm{CO}_{2}$ capture, storage and utilization (CCSU) was not modeled, as the distribution and use phases of the product and coproducts' life cycles were not within the scope of this study.

\subsection{Allocation}

There were several coproducts associated with each scenario. The energy-based allocation method, as adopted by the European Parliament [38], was applied to allocate the environmental impacts between the main products and coproducts.

\section{Results}

The life cycle impact assessment used the ReCiPe midpoint hierarchist method in SimaPro with 18 impact categories by default. The Inland Freshwater scenario was used as the base case scenario, and the values of all impact categories were normalized as $100 \%$ for comparison. The Coastal Seawater scenario demonstrated reductions in 15 of these impact categories, and the results were the same in the remaining 3 impact categories relative to the Inland Freshwater scenario. The environmental impact reduction was primarily in the water depletion category, with a decrease of $31.2 \%$. Climate change, natural land transformation, urban land occupation and fossil depletion were all reduced by $3.5-5.5 \%$. Agricultural land occupation showed no change, as the modeled first-generation feedstock production relies on arable land in both scenarios (Figure 4 and Table 4).

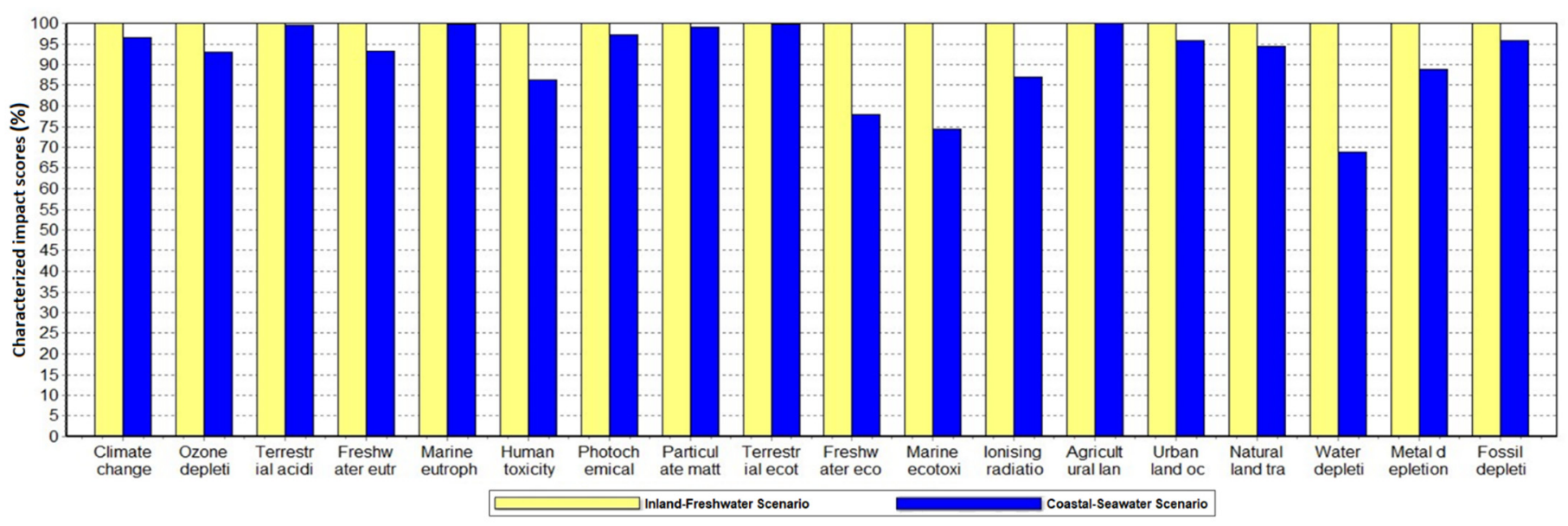

Figure 4. Complete life cycle environmental impacts of the two scenarios of bioethanol production. The data have been characterized for direct comparison of the scenarios in each impact category based on ethanol (95\% in solution state) from sugar beet, Alloc Def, U. 
Table 4. Complete life cycle environmental impacts of the two scenarios of bioethanol production.

\begin{tabular}{|c|c|c|c|}
\hline Impact Category & Unit & Inland Freshwater & Coastal Seawater \\
\hline Climate change & $\mathrm{kg} \mathrm{CO}_{2} \mathrm{eq}$ & 1.30 & 1.26 \\
\hline Ozone depletion & $\mathrm{kg} \mathrm{CFC-11} \mathrm{eq}$ & $4.37 \times 10^{-8}$ & $4.06 \times 10^{-8}$ \\
\hline Terrestrial acidification & $\mathrm{kg} \mathrm{SO}_{2} \mathrm{eq}$ & $4.13 \times 10^{-2}$ & $4.11 \times 10^{-2}$ \\
\hline Freshwater eutrophication & $\mathrm{kg} P$ eq & $3.96 \times 10^{-4}$ & $3.69 \times 10^{-4}$ \\
\hline Marine eutrophication & $\operatorname{kg~N~eq~}$ & $2.44 \times 10^{-2}$ & $2.44 \times 10^{-2}$ \\
\hline Human toxicity & kg 1,4-DB eq & $1.33 \times 10^{-1}$ & $1.15 \times 10^{-1}$ \\
\hline Photochemical oxidant formation & kg NMVOC & $3.30 \times 10^{-3}$ & $3.21 \times 10^{-3}$ \\
\hline Particulate matter formation & kg PM10 eq & $6.05 \times 10^{-3}$ & $5.99 \times 10^{-3}$ \\
\hline Terrestrial ecotoxicity & $\operatorname{kg} 1,4-\mathrm{DB}$ eq & $1.82 \times 10^{-3}$ & $1.81 \times 10^{-3}$ \\
\hline Freshwater ecotoxicity & $\operatorname{kg} 1,4-\mathrm{DB}$ eq & $2.30 \times 10^{-3}$ & $1.79 \times 10^{-3}$ \\
\hline Marine ecotoxicity & $\mathrm{kg} 1,4-\mathrm{DB}$ eq & $1.66 \times 10^{-3}$ & $1.23 \times 10^{-3}$ \\
\hline Ionizing radiation & kBq U235 eq & $1.38 \times 10^{-1}$ & $1.20 \times 10^{-1}$ \\
\hline Agricultural land occupation & $\mathrm{m}^{2} \mathrm{a}$ & 1.47 & 1.47 \\
\hline Urban land occupation & $\mathrm{m}^{2} \mathrm{a}$ & $3.14 \times 10^{-3}$ & $3.01 \times 10^{-3}$ \\
\hline Natural land transformation & $\mathrm{m}^{2}$ & $1.48 \times 10^{-5}$ & $1.40 \times 10^{-5}$ \\
\hline Water depletion & $\mathrm{m}^{3}$ & $9.13 \times 10^{-1}$ & $6.28 \times 10^{-1}$ \\
\hline Metal depletion & $\mathrm{kg} \mathrm{Fe} \mathrm{eq}$ & $3.84 \times 10^{-3}$ & $3.41 \times 10^{-3}$ \\
\hline Fossil depletion & $\mathrm{kg}$ oil eq & $2.43 \times 10^{-1}$ & $2.32 \times 10^{-1}$ \\
\hline
\end{tabular}

The climate change impact category describes the effect of the system on the global temperature reported in the 'year per kilogram $\mathrm{CO}_{2}$ equivalent' $\left(\mathrm{kg} \mathrm{CO}_{2} \mathrm{eq}\right)$, based on the most recent IPCC 100-year global warming potential [39]. The overall Coastal Seawater scenario demonstrated a $3.5 \%$ reduction in the climate change impact (Figure 4). Figure 5 shows that climate change was a relatively impactful category with European normalization factors applied. This represents a significant improvement upon the Inland Freshwater scenario. It worth noting that the use of seawater in washing the sugar beets alone enabled a 1.5\% reduction in the climate change impact. The complete impact assessment results for beet washing only in both scenarios are indicated in Figure 6 and Table 5.

Table 5. Complete life cycle environmental impacts of the two scenarios of bioethanol production for the beet washing step only.

\begin{tabular}{|c|c|c|c|}
\hline Impact Category & Unit & Inland Freshwater & Coastal Seawater \\
\hline Climate change & $\mathrm{kg} \mathrm{CO}_{2} \mathrm{eq}$ & $8.90 \times 10^{-2}$ & $8.76 \times 10^{-2}$ \\
\hline Ozone depletion & kg CFC-11 eq & $3.50 \times 10^{-10}$ & $2.78 \times 10^{-10}$ \\
\hline Terrestrial acidification & $\mathrm{kg} \mathrm{SO}_{2} \mathrm{eq}$ & $4.62 \times 10^{-3}$ & $4.61 \times 10^{-3}$ \\
\hline Freshwater eutrophication & $\mathrm{kg} P$ eq & $4.10 \times 10^{-5}$ & $3.97 \times 10^{-5}$ \\
\hline Marine eutrophication & $\mathrm{kg} \mathrm{N} \mathrm{eq}$ & $2.85 \times 10^{-3}$ & $2.85 \times 10^{-3}$ \\
\hline Human toxicity & kg 1,4-DB eq & $1.08 \times 10^{-2}$ & $9.92 \times 10^{-3}$ \\
\hline Photochemical oxidant formation & kg NMVOC & $1.21 \times 10^{-4}$ & $1.18 \times 10^{-4}$ \\
\hline Particulate matter formation & kg PM10 eq & $6.28 \times 10^{-4}$ & $6.26 \times 10^{-4}$ \\
\hline Terrestrial ecotoxicity & kg $1,4-\mathrm{DB}$ eq & $2.07 \times 10^{-4}$ & $2.07 \times 10^{-4}$ \\
\hline Freshwater ecotoxicity & $\mathrm{kg} 1,4-\mathrm{DB}$ eq & $1.51 \times 10^{-4}$ & $1.21 \times 10^{-4}$ \\
\hline Marine ecotoxicity & kg 1,4-DB eq & $6.18 \times 10^{-5}$ & $4.09 \times 10^{-5}$ \\
\hline Ionizing radiation & $\mathrm{kBq} U 235 \mathrm{eq}$ & $1.63 \times 10^{-3}$ & $9.43 \times 10^{-4}$ \\
\hline Agricultural land occupation & $\mathrm{m}^{2} \mathrm{a}$ & $1.70 \times 10^{-1}$ & $1.70 \times 10^{-1}$ \\
\hline Urban land occupation & $\mathrm{m}^{2} \mathrm{a}$ & $1.97 \times 10^{-5}$ & $1.30 \times 10^{-5}$ \\
\hline Natural land transformation & $\mathrm{m}^{2}$ & $9.13 \times 10^{-8}$ & $5.31 \times 10^{-8}$ \\
\hline Water depletion & $\mathrm{m}^{3}$ & $2.35 \times 10^{-2}$ & $7.06 \times 10^{-3}$ \\
\hline Metal depletion & $\mathrm{kg}$ Fe eq & $3.19 \times 10^{-5}$ & $2.90 \times 10^{-5}$ \\
\hline Fossil depletion & $\mathrm{kg}$ oil eq & $7.72 \times 10^{-3}$ & $7.40 \times 10^{-3}$ \\
\hline
\end{tabular}



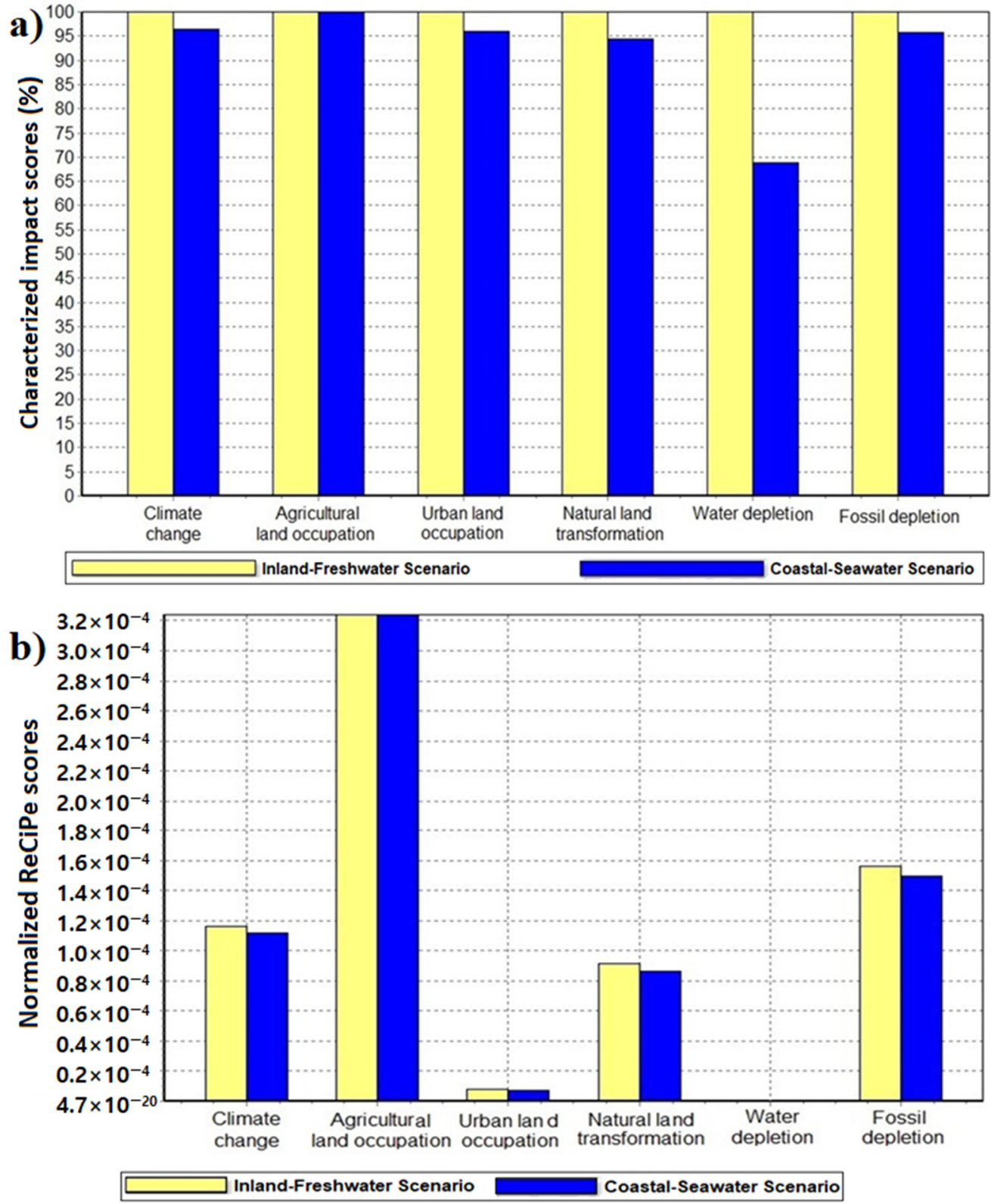

Figure 5. Comparative life cycle environmental impacts of the two scenarios of bioethanol production. (a) The data have been characterized for direct comparison of the scenarios in six impact categories based on ethanol (95\% in solution state) from sugar beet, Alloc Def, U. (b) The values have been normalized for their relative significance using the ReCiPe European normalization method on SimaPro.

The water depletion describes the freshwater consumption in cubic meters $\left(\mathrm{m}^{3}\right)$ of the system. Only groundwater and surface waters (i.e., freshwater sources) were considered. Seawater use in the Coastal Seawater scenario displaced tap water and therefore did not contribute to water depletion. The impact assessment showed that the Coastal Seawater scenario had $31.2 \%$ less impact on water depletion than the Inland Freshwater scenario (Figure 3). In the beet washing stage, the use of seawater instead of freshwater reduced the water depletion impact of the clean sugar beet by 70\% (Figure 6 and Table 5). 


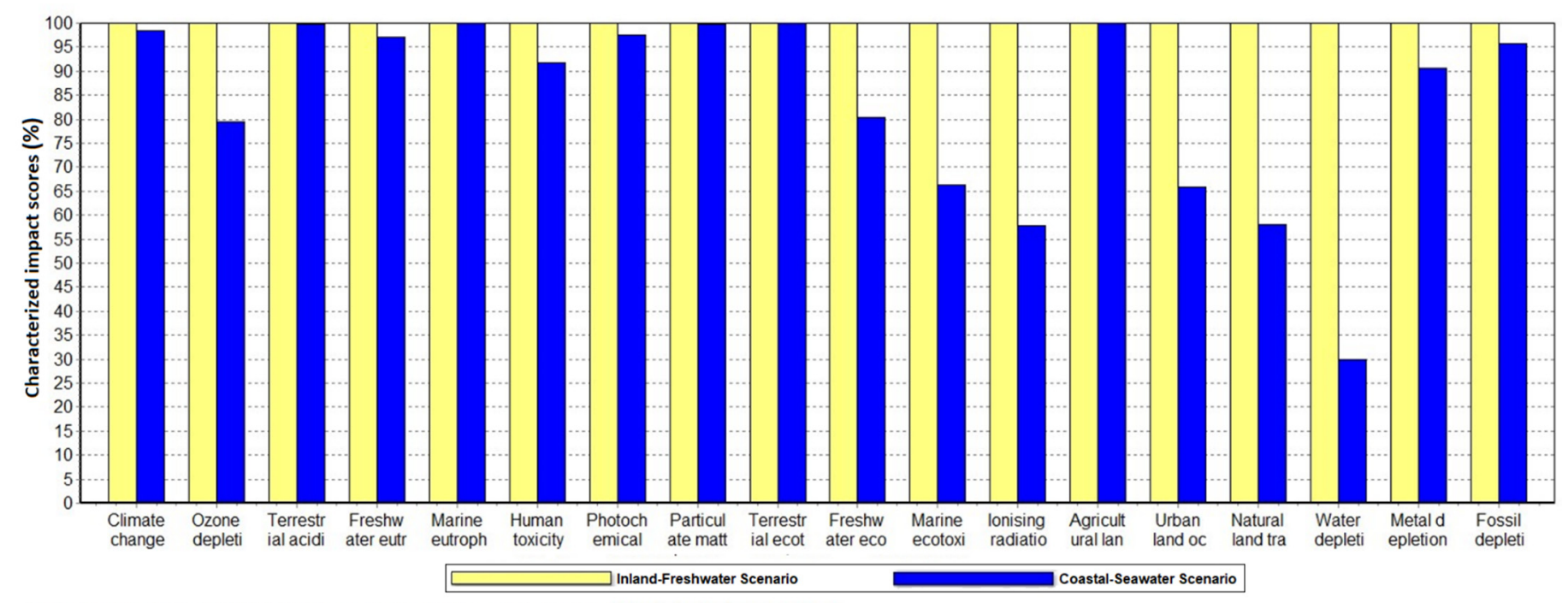

Method: ReCiPe Midpoint (H) V1.10 / Europe Recipe H / Characterization / Excluding infrastructure processes

Figure 6. Complete impact assessment results for beet washing only in each scenario. The graph is characterized for direct comparison in 18 impact categories.

The land use category factors in the type of land occupied by the process and the inputs to the process. The units for occupation are in area and time occupied $\left(\mathrm{m}^{2} \cdot\right.$ annum), while for transformation, it is the area $\left(\mathrm{m}^{2}\right)$. Agricultural land occupation remained identical in the production of clean sugar beet and the endpoint production of bioethanol and its coproducts. The normalized graph (Figure 5) shows that this was by far the most impactful of the selected categories for bioethanol production in Europe. Urban occupation was reduced in the Coastal Seawater scenario by $34.2 \%$ for sugar beet washing (Figure 6 and Table 5) and $4.1 \%$ in the overall process (Figure 4). Natural land transformation was the most significantly reduced land use category, with reductions in the beet washing and overall process of $41.9 \%$ (Figure 6 and Table 5) and 5.5\% (Figure 5), respectively.

The Coastal Seawater scenario showed a reduction of $4.2 \%$ in the fossil depletion impact category in both the washing stage and the overall process (Figure 4). The normalized chart indicates that this was a significant category when the results were calculated using European normalization factors (Figure 5).

\section{Discussion}

\subsection{Water Depletion Impact and Other Benefits of Seawater Fermentation}

Water in the Coastal Seawater scenario was directly piped from the sea, a source that does not factor into the WF as freshwater does. In the initial stage of water use in the process, sugar beet washing, the use of seawater had a $70 \%$ lower water depletion impact from the clean sugar beet than the Inland Freshwater scenario. Overall, the Coastal Seawater scenario achieved a $31.2 \%$ net reduction in the water depletion impact compared with the Inland Freshwater scenario. This demonstrates the potential of seawater usage in industrial-scale bioethanol production to achieve a significant reduction in the water depletion impact.

The normalization chart (Figure 5) reveals that water depletion was a relatively low impact category when European normalization factors were applied. Water scarcity does not rank among the main environmental issues in most of Europe, and so while the water depletion impact was significantly reduced in the Coastal Seawater scenario, other impacts had more relative importance to the overall environmental impact of European bioethanol.

There is a high likelihood that through use of a seawater fermentation medium, highpurity (97-99\%) ethanol can be obtained for a fraction of the energetic cost associated with freshwater-based ethanol purification. Pure ethanol production would usually be done by a three-step extractive distillation of the fermentation broth: distillation to $95 \%$ pure 
ethanol with $5 \%$ water, followed by extractive distillation requiring a solvent to increase the purity by water removal and finally distillation to remove the solvent. This process is highly energy intensive, as estimated by Lee and Pahl [40], where 50-80\% of the overall process energy is required for producing highly pure ethanol. The addition of salts to the fermentation broth prior to extractive distillation has been suggested as a means to enhance ethanol recovery, reducing the number of stages to a single distillation [41]. In the coastal case, sodium chloride salt from the seawater medium is already dissolved in the solution and thus may improve extraction efficiency and energy balance, which will be the focus of future research.

The scenarios were modeled with a single distillation stage, yielding 95\% pure bioethanol in the Inland Freshwater scenario. The Coastal Seawater scenario may have yielded a higher purity due to the salt's effect, and so it produced higher-value bioethanol. However, this requires support with practical data. The purity of the bioethanol produced has a direct link with its economic value. Anhydrous ethanol is necessary for fuel use, as water can induce corrosion and rust in engines.

\subsection{Climate Change and CCS Technology}

Bioenergy production has been suggested as an ideal industry for coupling with CCS technology [42], enabling a potential overall carbon-negative process. The high purity stream of $\mathrm{CO}_{2}$ exiting the fermentation vessel can be easily collected for compression and storage, as compared with crude oil refineries which emit a range of gases and require a capture technology to filter emissions and far more processing, thus leading to higher costs [8].

The CCS technology that is incorporated into conventional production, on which the Inland Freshwater scenario in this study was modeled, tends to be short-term. Sequestration in products such as carbonated beverages delays the $\mathrm{CO}_{2}$ release for the shelf life of the product. On the other hand, sequestration in the deep sea, such as geological injection, is a long-term storage solution [43]. Offshore storage has been proposed, as offshore continental shelves offer significant capacities, which are necessary to meet the 2050 climate goals [44]. Owing to the location of the Coastal Seawater scenario, offshore oceanic injection is likely to be a feasible solution to store the $\mathrm{CO}_{2}$.

In this study, the climate change impact was reduced by $3.5 \%$. The normalization factors for Europe revealed that this category is of relatively high importance, which amplifies the reduction in the overall impact of the product by implementation of the Coastal Seawater scenario.

\subsection{Coproduct Profiles and Economic Discussion}

The investigated scenarios for bioethanol production yielded different coproduct profiles. Utilization of waste streams (i.e., beet pulp and sea salt) adds value to the overall process and can thus potentially improve the economic viability of biofuels. A comprehensive techno-economic analysis to evaluate the financial performance can be the focus of future work. Both scenarios generate biogenic $\mathrm{CO}_{2}$ through fermentation that can be stored to increase the CCS ability of the bioethanol. However, there is potential for more efficient $\mathrm{CO}_{2}$ storage in the case of the Coastal Seawater scenario. The $\mathrm{CO}_{2}$ generated during the fermentation at coastal locations can be stored safely and permanently in the deep sea (at $3000 \mathrm{~m}$ deep or more), as the $\mathrm{CO}_{2}$ becomes a heavy liquid that sinks to the ocean floor $[8,45]$.

In addition, both scenarios produced beet pulp as animal feed, but in the case of the Coastal Seawater scenario, beet pup was salted as a result of washing with seawater or by adding sea salt to the pulp following the juicing stage. In addition, if the process did not recycle the yeast for the next fermentation cycles, the salted yeast would be added to the pulp to produce a high-value sea salted animal feed. Salts are usually added to the feed, either by the retailer or by the consumer, as animals require the nutrients. The production 
of sea salted animal feed in the coastal scenario comes without the expense of additive sea salt and can be presumably marketed at a greater value than unsalted feed.

In addition, the use of seawater in the Coastal Seawater scenario enabled the additional production of distilled water and sea salt, neither of which were present in the Inland Freshwater scenario. Sodium chloride, other minerals and trace elements are naturally contained in seawater. These remain dissolved through to the distillation stage, at which point they are precipitated out, resulting in water and sea salt.

Additionally, the addition of sea salt and distilled water to the coproduct profile further improved the economic situation in the Coastal Seawater scenario. Originating from the sea, the water is desalinated in the process of distillation, and so it is converted from a free and abundant resource to a valuable product. By contrast, the Inland Freshwater scenario, which reflects current practices, treats this distilled water as waste, even though it is usually required to be recycled in the fermentation medium to reduce the freshwater intake and the total WF of the process. However, reuse of the distilled water in the fermentation media is not desired because if it is used, additional minerals need to be added to the fermentation medium due to the lower mineral content compared with tap water. Added revenue streams without significant additional costs make the Coastal Seawater scenario the economically preferred scenario.

The value of water as a product dictates whether this element of the proposed coastal biorefinery balances the economic system. As a product of extractive distillation, the produced desalinated water would be non-potable. This is due to trace amounts of the solvent applied for ethanol recovery. Water utility companies identify the demand for non-potable water, which lends a market value to this product. The purity of the water resulting from this process is not yet known. The water treatment required to achieve a potable product may be worth the cost.

Implementation of a biorefinery operating in seawater fermentation would be more beneficial to countries facing extreme water scarcity that have access to seawater. The value of desalinated water in these countries would be more economically favorable than in countries with plentiful freshwater resources. Desalination is an expensive method to produce water alone, but as part of the coproduct profile of bioethanol fuel production, the economics may be more balanced.

\subsection{Assumptions and Limitations}

This study was conducted under the assumption that the Coastal Seawater scenario utilized a similar amount of electricity as in the Inland Freshwater scenario. However, experimental investigation may indicate that the Coastal Seawater scenario consumes less overall energy compared with the Inland Freshwater scenario, especially in the beet washing and ethanol distillation steps, and therefore, it may produce more surplus electricity. In addition, this study assumed that both scenarios required the addition of similar amounts of sodium sulfate in the fermentation media. However, typical seawater ( $3.5 \%$ salinity) contains enough sodium $(10.76 \mathrm{~g} / \mathrm{kg})$ and sulfate $(2.71 \mathrm{~g} / \mathrm{kg})$ [46], and therefore, the addition of sodium sulfate could be eliminated in the Coastal Seawater scenario. Anti-foam could be also eliminated or at least reduced in the Coastal Seawater scenario, because the high concentration of salt in seawater could work as an anti-foam [47]. In addition, unlike the Inland Freshwater scenario, part of the distilled water produced in the Coastal Seawater scenario can be reused in the system, eliminating the need for external distilled water for cooling. Taking all these points into consideration for remodeling the Coastal Seawater scenario would lead to improved environmental and economic results.

Furthermore, the bioethanol production rate and productivity were assumed to be equivalent in both scenarios. This was because the Coastal Seawater model would ideally involve the use of a marine yeast strain for fermentation in a seawater-based medium. Marine yeast can produce bioethanol using seawater at almost the same rate as industrial terrestrial yeast using freshwater. The marine S. cerevisiae strain AZ65 recorded ethanol production at a rate of $1.62 \mathrm{~g} / \mathrm{L} / \mathrm{h}$ using seawater as compared with $1.65 \mathrm{~g} / \mathrm{L} / \mathrm{h}$ by terrestrial 
strain NCYC2592 using freshwater [19], and it reached a maximum ethanol productivity of $4.15 \mathrm{~g} / \mathrm{L} / \mathrm{h}$ using a YPD-seawater medium and $2.46 \mathrm{~g} / \mathrm{L} / \mathrm{h}$ using a molasses-seawater medium [24]. A specific HPLC method for simultaneously measuring chloride, sugars, organic acids and alcohols in seawater samples was used in this research for accurate measurement of the ethanol and the remaining sugars [48]. The production rate and productivity of seawater bioethanol can be improved by further optimization of the fermentation parameters and improving the marine yeast strain.

On the other hand, the cost of construction of both the bioethanol plant and the oceanic $\mathrm{CO}_{2}$ injection site were not included in this study. This improved the comparability between the scenarios, assuming that these structures had long enough lifetimes that these capital costs could be paid back quickly. However, the capital investment in the two scenarios is likely to differ, which can be addressed in future work.

\subsection{Future Perspectives: Toward a Coastal Integrated Marine Biorefinery (CIMB) System}

In this analysis, the cultivation and harvesting of the feedstock subsystem produced identical results between the coastal and Inland Freshwater scenarios. This resulted in no change in agricultural land use between the two scenarios (Figure 4). The European normalization factors, however, showed that this was by far the most important of the selected categories (Figure 5).

Additionally, although the Coastal Seawater scenario produced freshwater, its water depletion impact was not negative. This shows that the volume of freshwater produced did not offset that used in the production process. In the Coastal Seawater scenario, seawater was applied to beet washing and the fermentation medium. However, the majority of the water depletion took place in the cultivation and harvesting.

This work was conducted to evaluate the environmental feasibility of the coastal setting and seawater use, with a view to then incorporate marine biomass (such as seaweed and marine microalgae) in the Coastal Seawater system to reach a fully marine-based biorefinery. This is predicted to greatly reduce the environmental impact of water depletion and land use, or agricultural land occupation to be specific. Further practical work will determine the processing requirements needed for marine biomass feedstock in a coastal biorefinery using a seawater medium. However, new scenarios should be comprehensively analyzed via environmental and social impact assessment using LCA and human health impact assessment using risk analysis to obtain comparable results [49,50].

Marine biomass sources including macro- and microalgae have potential for use as feedstock. They do not require freshwater or land for cultivation and are therefore a desirable feedstock. A coastal location puts the production process in close proximity to marine resources. In addition to the access to seawater and marine biomass, the coastal location offers other potential benefits that have not been included in this study due to a lack of data availability and research time. As the concept gains traction, further integration with other technology systems could be explored. Another benefit of a coastal location is the ease of transportation by sea. The fuel product as well as the coproducts (water, salt, animal feed and LimeX) could be exported by freight shipping, widening access to the fuel beyond its immediate area. Thus, a marine-based biorefinery in a coastal location is likely to improve both the sustainability and feasibility of bioethanol production [37,51,52], contributing to the global effort to achieve environmental targets.

Furthermore, the coastal location improves accessibility to renewable power sources. In this analysis where electricity was necessary, such as in $\mathrm{CO}_{2}$ compression and beet pulp drying, the source of the electricity was from the grid, which included non-renewable sources. A direct connection to renewable sources, such as offshore windfarms and wave energy sites, could be integrated into the process to further improve the environmental impact toward net zero targets. This translates to reduced transport costs-both monetary and environmental—and may have further benefits. 


\title{
5. Conclusions
}

The LCA presented in this study demonstrated the value of a coastal biorefinery using marine yeasts and a seawater medium in reducing the environmental impact of bioethanol production. Environmental impact reduction was primarily in the water depletion category, with a decrease of $31.2 \%$. Climate change, natural land transformation, urban land occupation and fossil depletion were all reduced by $3.5-5.5 \%$. Agricultural land occupation saw no change due to the modeled first-generation feedstock, which relies on arable land for feedstock production. Coupling with CCS and water desalination showed environmental improvements upon current bioethanol production. Further opportunities for environmental impact reduction, owing to the coastal location, are also discussed, particularly regarding climate change and land use. Further work is suggested to integrate marine biomass (seaweed and marine microalgae) for a complete integrated marine biorefinery system based on coastal sites. This would immensely reduce the water and carbon footprint for bioethanol, likely to net negative values, and increase the economic feasibility of the process. Utilization of the marine resources in a marine biorefinery system based on coastal locations for the intensive production of biofuels and biobased products has the potential for speeding up the global effort in climate change mitigation as well as water, food and energy security.

Author Contributions: Conceptualization, A.S.Z.; methodology, C.E.C.; software, C.E.C.; validation, C.E.C., A.S.Z. and F.M.; formal analysis, C.E.C.; investigation, C.E.C. and A.S.Z.; resources, C.E.F. and A.S.Z.; data, C.E.C. and F.M.; writing-original draft preparation, C.E.C. and A.S.Z.; writingreview and editing, F.M. and C.E.F.; visualization, A.S.Z. and C.E.F.; supervision, A.S.Z.; project administration, A.S.Z. and C.E.F.; funding acquisition, A.S.Z. and C.E.F. All authors have read and agreed to the published version of the manuscript.

Funding: This research received no external funding.

Institutional Review Board Statement: Not applicable.

Informed Consent Statement: Not applicable.

Acknowledgments: The authors would like to thank R. Camilla Thompson from the School of Engineering at the University of Edinburgh for her great assistance and guidance with the SimaPro software.

Conflicts of Interest: The authors declare no conflict of interest.

\begin{abstract}
Abbreviations
CMB: coastal marine biorefinery, IF: Inland-Freshwater, LCA: life cycle assessment, GHG: greenhouse gas, $\mathrm{CO}_{2}$ : carbon dioxide, $\mathrm{CCS}$ : carbon capture and storage, $\mathrm{CCSU}$ : carbon capture storage and utilization, LUC: land use change, WF: water footprint, YPD: yeast extract peptone dextrose, NCYC: National Collection of Yeast Cultures, SW: seawater, SB: sugar beet, kWh: kilowatt-hour, kg: kilogram, Et: ethanol, MJ: mega joule, eq: equivalent, IPCC: Intergovernmental Panel on Climate Change, CIMB: Coastal Integrated Marine Biorefinery.
\end{abstract}

\section{References}

1. United Nations. Paris Agreement; United Nations: Paris, France, 2016; pp. 1-27.

2. Ritchie, H.; Rosner, M. $\mathrm{CO}_{2}$ and Greenhouse Gas Emissions. 2020. Available online: https://ourworldindata.org/co2-and-othergreenhouse-gas-emissions (accessed on 20 April 2020).

3. Duque, A.; Álvarez, C.; Doménech, P.; Manzanares, P.; Moreno, A.D. Advanced Bioethanol Production: From Novel Raw Materials to Integrated Biorefineries. Processes 2021, 9, 206. [CrossRef]

4. Fulton, L.M.; Lynd, L.R.; Körner, A.; Greene, N.; Tonachel, L.R. The need for biofuels as part of a low carbon energy future. Biofuels Bioprod. Biorefining 2015, 9, 476-483. [CrossRef]

5. Zhang, J.; Fisher, T.S.; Ramachandran, P.V.; Gore, J.P.; Mudawar, I. A review of heat transfer issues in hydrogen storage technologies. J. Heat Transf. 2005, 127, 1391-1399. [CrossRef]

6. Felderhoff, M.; Weidenthaler, C.; von Helmolt, R.; Eberle, U. Hydrogen storage: The remaining scientific and technological challenges. Phys. Chem. Chem. Phys. 2007, 9, 2643-2653. [CrossRef] 
7. Den Boer, E.; Aarnink, S.; Kleiner, F.; Pagenkopf, J. Zero Emissions Trucks: An Overview of State-of-the-Art Technologies and Their Potential. 2013. Available online: https://theicct.org/sites/default/files/publications/CE_Delft_4841_Zero_emissions_ trucks_Def.pdf (accessed on 11 August 2021).

8. Metz, B.; Davidson, O.; De Coninck, H.; Loos, M.; Meyer, L. IPCC Special Report on Carbon Dioxide Capture and Storage; Cambridge University Press: Cambridge, UK, 2005. Available online: https://www.ipcc.ch/site/assets/uploads/2018/03/srccs_ wholereport-1.pdf (accessed on 11 August 2021).

9. GlobalCCSInstitute. Global Status of CCS 2019: Targeting Climate Change; The Global CCS Institute: Melbourne, Australia, 2019.

10. Pal, A. Blending of ethanol in gasoline: Impact on SI engine performance and emissions. Int. J. Therm. Technol. 2014, 4, 1-5.

11. Al-Hasan, M. Effect of ethanol-unleaded gasoline blends on engine performance and exhaust emission. Energy Convers. Manag. 2003, 44, 1547-1561. [CrossRef]

12. Muñoz, M.; Heeb, N.V.; Haag, R.; Honegger, P.; Zeyer, K.; Mohn, J.; Comte, P.; Czerwinski, J. Bioethanol blending reduces nanoparticle, $\mathrm{PAH}$, and alkyl-and nitro-PAH emissions and the genotoxic potential of exhaust from a gasoline direct injection flex-fuel vehicle. Environ. Sci. Technol. 2016, 50, 11853-11861. [CrossRef]

13. Department for Transport. Fuelling a Greener Future: E10 Petrol Set for September 2021 Launch. 2021. Available online: https: / / www.gov.uk/government/news/fuelling-a-greener-future-e10-petrol-set-for-september-2021-launch (accessed on 4 March 2021).

14. Bailey, B.K. Performance of ethanol as a transportation fuel. In Handbook on Bioethanol; Routledge: Abingdon, UK, 2018; pp. 37-60.

15. Speidel, H.K.; Ahmed, I. Biodegradability Characteristics of Current and Newly-Developed Alternative Fuels; SAE Technical Paper 1999-01-351; SAE International: Warrendale, PA, USA, 1999. [CrossRef]

16. Dias De Oliveira, M.E.; Vaughan, B.E.; Rykiel, E.J. Ethanol as fuel: Energy, carbon dioxide balances, and ecological footprint. BioScience 2005, 55, 593-602. [CrossRef]

17. European Union. Directive (EU) 2018/2001 of the European Parliament and of the Council of 11 December 2018 on the promotion of the use of energy from renewable sources (Text with EEA relevance.). Off. J. Eur. Union 2018, 328, 82-209.

18. Liu, X.V.; Hoekman, S.K.; Broch, A. Potential water requirements of increased ethanol fuel in the USA. Energy Sustain. Soc. 2017, 7, 18. [CrossRef]

19. Zaky, A.; Greetham, D.; Tucker, G.; Du, C. The establishment of a marine focused biorefinery for bioethanol production using seawater and a novel marine yeast strain. Sci. Rep. 2018, 8, 12127. [CrossRef]

20. Gerbens-Leenes, W.; Hoekstra, A.Y.; van der Meer, T.H. The water footprint of bioenergy. Proc. Natl. Acad. Sci. USA 2009, 106, 10219-10223. [CrossRef] [PubMed]

21. Gerbens-Leenes, P. Green, blue and grey bioenergy water footprints, a comparison of feedstocks for bioenergy supply in 2040. Environ. Process. 2018, 5, 167-180. [CrossRef]

22. de María, P.D. On the use of seawater as reaction media for large-scale applications in biorefineries. ChemCatChem 2013, 5, 1643-1648. [CrossRef]

23. Zaky, A.; Greetham, D.; Louis, E.; Tucker, G.; Du, C. A New Isolation and Evaluation Method for Marine-Derived Yeast spp. with Potential Applications in Industrial Biotechnology. J. Microbiol. Biotechnol. 2016, 26, 1891-1907. [CrossRef]

24. Zaky, A.S.; French, C.E.; Tucker, G.A.; Du, C. Improving the productivity of bioethanol production using marine yeast and seawater-based media. Biomass Bioenergy 2020, 139, 105615. [CrossRef]

25. International Organization for Standardization. Environmental Management: Life Cycle Assessment; Requirements and Guidelines; ISO: Geneva, Switzerland, 2006.

26. Goedkoop, M.; Oele, M.; de Schryver, A.; Vieira, M.; Hegger, S. SimaPro Database Manual Methods Library; PRé Consultants: Amersfoort, The Netherlands, 2008; pp. 22-25.

27. Wernet, G.; Bauer, C.; Steubing, B.; Reinhard, J.; Moreno-Ruiz, E.; Weidema, B. The ecoinvent database version 3 (part I): Overview and methodology. Int. J. Life Cycle Assess. 2016, 21, 1218-1230. [CrossRef]

28. Durlinger, B.; Tyszler, M.; Scholten, J.; Broekema, R.; Blonk, H.; Beatrixstraat, G. Agri-Footprint; a Life Cycle Inventory database covering food and feed production and processing. In Proceedings of the 9th International Conference on Life Cycle Assessment in the Agri-Food Sector, San Francisco, CA, USA, 8-10 October 2014; pp. 310-317.

29. Vierhout, R. Renewable Ethanol: Driving Jobs, Growth and Innovation throughout Europe; State of the Industry Report; ePure European Renewable Ethanol Association, 2014. Available online: https:/ /www.liquid-energy.ch/wp/wp-content/uploads/2014-06-14 -Ethanol-State-of-the-Industry-Report-2014.pdf (accessed on 11 August 2021).

30. Šantek, B.; Gwehenberger, G.; Šantek, M.I.; Narodoslawsky, M.; Horvat, P. Evaluation of energy demand and the sustainability of different bioethanol production processes from sugar beet. Resour. Conserv. Recycl. 2010, 54, 872-877. [CrossRef]

31. Mundi, G.S.; Zytner, R.G.; Warriner, K. Fruit and vegetable wash-water characterization, treatment feasibility study and decision matrices. Can. J. Civ. Eng. 2017, 44, 971-983. [CrossRef]

32. Campiotti, C.A.; Latini, A.; Scoccianti, M.; Biagiotti, D.; Giagnacovo, G.; Viola, C. Energy efficiency in Italian fruit and vegetables processing industries in the EU agro-food sector context. Riv. Studi Sulla Sostenibilita 2014, 2, 159-174.

33. Mortimer, N.; Elsayed, M.; Horne, R. Energy and Greenhouse Gas Emissions for Bioethanol Production from Wheat Grain and Sugar Beet; Resources Research Unit School of Environment and Development, Sheffield Hallam University: Sheffield, UK, 2004.

34. Rao, P.; Morrow, W.R., III; Aghajanzadeh, A.; Sheaffer, P.; Dollinger, C.; Brueske, S.; Cresko, J. Energy considerations associated with increased adoption of seawater desalination in the United States. Desalination 2018, 445, 213-224. [CrossRef] 
35. Pfromm, P.H. The minimum water consumption of ethanol production via biomass fermentation. Open Chem. Eng. J. 2008, 2, 1-5. [CrossRef]

36. Aspelund, A.; Jordal, K. Gas conditioning-The interface between $\mathrm{CO}_{2}$ capture and transport. Int. J. Greenh. Gas Control 2007, 1, 343-354. [CrossRef]

37. Zaky, A.S. Marine Fermentation, the Sustainable Approach for Bioethanol Production. EC Microbiol. 2017, 25-27. Available online: https:/ / www.ecronicon.com/eco16/pdf/ECMI-01-ECO-11.pdf (accessed on 11 August 2021).

38. European Commission. Directive of the European Parliament and of the Council on the Promotion of the Use of Energy from Renewable Sources; European Commission: Brussels, Belgium, 2008.

39. Stocker, T.; Qin, D.; Plattner, G.; Tignor, M.; Allen, S.; Boschung, J.; Nauels, A.; Xia, Y.; Bex, B.; Midgley, B. IPCC, 2013: Climate Change 2013: The Physical Science Basis. Contribution of Working Group I to the Fifth Assessment Report of the Intergovernmental Panel on Climate Change; IPCC: Cambridge, UK; New York, NY, USA, 2013. Available online: https://www.ipcc.ch/site/assets/uploads/ 2017/09/WG1AR5_Frontmatter_FINAL.pdf (accessed on 11 August 2021).

40. Lee, F.M.; Pahl, R.H. Solvent screening study and conceptual extractive distillation process to produce anhydrous ethanol from fermentation broth. Ind. Eng. Chem. Process Des. Dev. 1985, 24, 168-172. [CrossRef]

41. Pinto, R.; Wolf-Maciel, M.; Lintomen, L. Saline extractive distillation process for ethanol purification. Comput. Chem. Eng. 2000, 24, 1689-1694. [CrossRef]

42. Budinis, S.; Krevor, S.; Mac Dowell, N.; Brandon, N.; Hawkes, A. An assessment of CCS costs, barriers and potential. Energy Strategy Rev. 2018, 22, 61-81. [CrossRef]

43. Laude, A.; Ricci, O.; Bureau, G.; Royer-Adnot, J.; Fabbri, A. $\mathrm{CO}_{2}$ capture and storage from a bioethanol plant: Carbon and energy footprint and economic assessment. Int. J. Greenh. Gas Control 2011, 5, 1220-1231. [CrossRef]

44. Schrag, D.P. Storage of carbon dioxide in offshore sediments. Science 2009, 325, 1658-1659. [CrossRef] [PubMed]

45. Rackley, S.A. (Ed.) Chapter 12-Ocean Storage. In Carbon Capture and Storage; Butterworth-Heinemann: Boston, MA, USA, 2010; pp. 267-286. [CrossRef]

46. Morcos, S.A. Chemical Composition of Seawater and the Variation of Calcium and Alkalinity. ICES J. Mar. Sci. 1970, 33, 126-133. [CrossRef]

47. Behera, M.R.; Varade, S.R.; Ghosh, P.; Paul, P.; Negi, A.S. Foaming in Micellar Solutions: Effects of Surfactant, Salt, and Oil Concentrations. Ind. Eng. Chem. Res. 2014, 53, 18497-18507. [CrossRef]

48. Zaky, A.S.; Pensupa, N.; Andrade-Eiroa, Á.; Tucker, G.A.; Du, C. A new HPLC method for simultaneously measuring chloride, sugars, organic acids and alcohols in food samples. J. Food Compos. Anal. 2017, 56, 25-33. [CrossRef]

49. Papong, S.; Rewlay-ngoen, C.; Itsubo, N.; Malakul, P. Environmental life cycle assessment and social impacts of bioethanol production in Thailand. J. Clean. Prod. 2017, 157, 254-266. [CrossRef]

50. Milazzo, M.F.; Spina, F. The use of the risk assessment in the life cycle assessment framework. Manag. Environ. Qual. Int. J. 2015, 26, 389-406. [CrossRef]

51. Zaky, A.S.; Tucker, G.A.; Daw, Z.Y.; Du, C. Marine yeast isolation and industrial application. FEMS Yeast Res. 2014, 14, 813-825. [CrossRef]

52. Greetham, D.; Zaky, A.; Makanjuola, O.; Du, C. A brief review on bioethanol production using marine biomass, marine microorganism and seawater. Curr. Opin. Green Sustain. Chem. 2018, 14, 53-59. [CrossRef] 